\title{
Facial nerve outcome and extent of resection in cystic versus solid vestibular schwannomas in radiosurgery era
}

\author{
Pinar Eser Ocak, MD, Ihsan Dogan, MD, Umut Ocak, MD, Cem Dinc, MD, and \\ Mustafa K. Başkaya, MD \\ Department of Neurological Surgery, University of Wisconsin Medical School, Madison, Wisconsin
}

OBJECTIVE Cystic vestibular schwannomas (CVSs) are a subgroup of vestibular schwannomas (VSs) that are reported to be associated with unpredictable clinical behavior and unfavorable postoperative outcomes. The authors aimed to review their experience with microsurgical treatment of CVSs in terms of extent of resection and postoperative facial nerve (FN) function and compare these outcomes with those of their solid counterparts.

METHODS Two hundred-eleven VS patients were treated surgically between 2006 and 2017. Tumors were defined as cystic when preoperative neuroimaging demonstrated cyst formation that was confirmed by intraoperative findings. Solid VS (SVSs) with similar classes were used for comparison. Clinical data of the patients were reviewed retrospectively, including clinical notes and images, as well as operative, pathology, and neuroradiology reports.

RESULTS Thirty-two patients (20 males and 12 females) with a mean age of 52.2 years (range 17-77 years) underwent microsurgical resection of 33 CVSs (mean size $3.6 \mathrm{~cm}$, range 1.5-5 cm). Forty-nine patients (26 males and 23 females) with a mean age of 49.9 years (range 21-75 years) underwent microsurgical resection of 49 SVSs (mean size $3 \mathrm{~cm}$, range 2-4.5 cm). All operations were performed via either a retrosigmoid or a translabyrinthine approach. Gross-total resection was achieved in 30 cases in the CVS group (90.9\%) and 37 in the SVS group (75.5\%). The main reason for subtotal and near-total resection was adherence of the tumor to the brainstem and/or FN in both groups. None of the patients with subtotal or near-total resection in the CVS group demonstrated symptomatic regrowth of the tumor during the mean follow-up period of 41.6 months (range 18-82 months). The FN was anatomically preserved in all patients in both groups. Good FN outcomes were achieved in 15 of CVS (grade I-II; 45.5\%) and 35 of SVS (71.4\%) surgeries at discharge. Good and fair FN functions were noted in 22 (grade I-II; 81.5\%) and 5 (grade III only; 18.5\%) of the CVS patients, respectively, at the 1-year follow-up; none of the patients showed poor FN function.

CONCLUSIONS Surgery of CVSs does not necessarily result in poor outcomes in terms of the extent of resection and FN function. Special care should be exercised to preserve anatomical continuity of the FN during surgery, since longterm FN function outcomes are much more satisfactory than short-term results. High rates of gross-total resection and good FN outcomes in our study may also suggest that microsurgery stands as the treatment of choice in select cases of large CVSs and SVSs in the era of radiosurgery.

https://thejns.org/doi/abs/10.3171/2017.12.FOCUS17667

KEY WORDS cystic vestibular schwannoma; solid vestibular schwannoma; facial nerve; gross-total resection

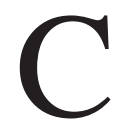
YSTIC vestibular schwannomas (CVSs) are notorious for being associated with adherence to the brainstem or cranial nerves and for lower rates of good facial nerve (FN) function after resection. $5,11,18,24,25,35$ Since we have not observed these findings in our CVS or solid vestibular schwannoma (SVS) series, we proposed to study our results. This also allowed us to compare CVS and SVS results in an era in which there is an increasing and obvious tendency toward radiosurgery in the treatment of vestibular schwannomas (VSs). The aim of this study was to retrospectively review our experience in the microsurgical treatment of CVS in terms of patient and

ABBREVIATIONS CVS = cystic VS; FN = facial nerve; GTR = gross-total resection; NTR = near-total resection; STR = subtotal resection; SVS = solid VS; VP = ventriculoperitoneal; $V S$ = vestibular schwannoma.

SUBMITTED November 1, 2017. ACCEPTED December 18, 2017.

INCLUDE WHEN CITING DOI: 10.3171/2017.12.FOCUS17667. 
tumor characteristics, extent of resection, postoperative short- and long-term FN function, and perioperative complications and to compare the findings with those of their solid counterparts.

\section{Methods}

Two hundred-eleven patients with VSs were treated surgically at the Department of Neurological Surgery, University of Wisconsin-Madison, between January 2006 and June 2017. After obtaining approval from the local institutional review board, we reviewed the patient data. The VSs were defined as cystic when preoperative MRI demonstrated cyst formation with contrast enhancement of the cyst wall. Cases were excluded from the study if these areas were not confirmed as cystic during surgery. CVSs were further classified as having multiple large thinwalled cysts, multiple small thick-walled cysts, single large thin-walled cysts, larger central thick-walled cysts, and a mixed pattern of small and large cysts. ${ }^{22,32}$ Tumor extension was classified as class T1 (purely intrameatal), class T2 (intra- and extrameatal), class T3a (filling the cerebellopontine cistern), class T3b (reaching the brainstem), class T4a (compressing the brainstem), and class T4b (severely displacing the brainstem and compressing the fourth ventricle). ${ }^{32}$ All CVSs demonstrated class T3 or T4 tumor extension; therefore, SVSs with similar classes were used for comparison. Patients with neurofibromatosis or bilateral VSs, recurrent VS, and class T1 or T2 SVS were excluded from the study. Thirty-three CVSs (in 32 patients) and 49 SVSs meeting the inclusion criteria were eventually identified and included in the study. The medical records of the patients were reviewed retrospectively, including preoperative and postoperative notes and images, as well as operative, pathology, and neuroradiology reports.

Preoperative hearing levels were classified as serviceable or nonserviceable according to the American Academy of Otolaryngology-Head and Neck Surgery classification. ${ }^{1}$ Postoperative FN function was evaluated according to the House-Brackmann grading system ${ }^{14}$ at discharge and at 3 months and 1 year postoperatively. The FN function was defined as good (House-Brackmann grade I-II), fair (grade III-IV), or poor (grade V-VI) ${ }^{30,33}$ Since many other published series have considered House-Brackmann grade I-III facial function as favorable, , $22,24,28,35,37,42$ we also included grade III function as favorable outcome. Among CVSs, patients in 2 cases who were lost during the follow-up period and those in 4 cases who did not yet reach the 1-year follow-up were excluded from the followup results of FN function. Similarly, 1 patient who was lost during the follow-up period and 3 patients who did not yet reach the 1-year follow-up in the SVS group were excluded from 1-year follow-up results of FN function.

Patients underwent microsurgical resection via either a retrosigmoid approach or translabyrinthine approach. FN monitoring was performed by a neurophysiologist in every case. All operations were performed by a single neurosurgeon (M.K.B.) and 2 neurootologists. The resection was considered as gross-total resection (GTR) when there was no obvious visible tumor at the time of surgery or on postoperative MRI. Near-total resection (NTR) was reported when less than $5 \%$ of the total tumor burden remained. The resection was considered as subtotal resection (STR) when the residual tumor was greater than $5 \%$ of the total tumor volume.

Significance of differences between groups was determined using the Fisher exact test and t-test. Statistical differences were considered significant if the $\mathrm{p}$ value was $<$ 0.05 .

\section{Results \\ Patient Characteristics}

The mean patient ages were 52.2 years (range 17-77 years) and 49.9 years (range 21-75 years) in the CVS and SVS groups, respectively. There were 20 male (62.5\%) and 12 female (37.5\%) patients in the CVS group, and 26 male (53.1\%) and 23 female (46.9\%) patients in the SVS group. There were no significant differences between the groups in terms of age $(\mathrm{p}=0.43)$ or sex $(\mathrm{p}=0.49$; Table 1$)$.

\section{Clinical Presentation CVS}

The most frequent initial symptom in the CVS group was ipsilateral hearing loss $(72.7 \%, \mathrm{n}=24)$, followed by tinnitus $(42.4 \%, \mathrm{n}=14)$, balance difficulties $(36.4 \%, \mathrm{n}=$ $12)$, and headaches $(18.2 \%, \mathrm{n}=6$; Table 2). The mean duration of symptoms was 15.7 months (range 2 days to 84 months). Findings were incidental in 2 cases (6.1\%), and patients in 2 cases $(6.1 \%)$ presented acutely. Patients in 12 cases (36.4\%) experienced worsening/acute onset of at least one of the symptoms within 30 days of presentation. Headache $(33.3 \%, \mathrm{n}=4)$ and sudden hearing loss $(33.3 \%$, $\mathrm{n}=4$ ) were the leading complaints, followed by balance difficulties $(16.7 \%, \mathrm{n}=2)$, alteration in taste $(8.3 \%, \mathrm{n}=1)$, and cerebellar dysfunction $(8.3 \%, \mathrm{n}=1)$ among the patients experiencing worsening/acute onset of symptoms. Patients in 25 cases $(75.8 \%)$ demonstrated nonserviceable hearing. There were 4 cases (12.1\%) of symptomatic hydrocephalus, and the patients required insertion of an external ventricular drain during the preoperative period. Of these, 1 patient required ventriculoperitoneal (VP) shunt placement due to persistent hydrocephalus (3\%). The mean follow-up period was 25.6 months (range 1-109 months).

\section{SVS}

The most frequent initial symptom was ipsilateral hearing loss $(95.9 \%, \mathrm{n}=47)$, followed by tinnitus $(46.9 \%, \mathrm{n}$ $=23)$, balance difficulties $(32.6 \%, \mathrm{n}=16)$, and vertigo/ dizziness $(20.4 \%, \mathrm{n}=10)$. Headache, facial sensory disturbances, ear fullness/pain, dysgeusia, and swallowing difficulties were less common as presenting symptoms (Table 2). The mean duration of symptoms was 23.9 months (range 15 days to 180 months). Findings were incidental in 1 case $(2 \%)$. Patients in 4 cases $(8.2 \%)$ experienced worsening of at least one of the symptoms within the last 30 days. Among them, patients in 2 cases $(50 \%)$ reported acute hearing loss, while 2 others $(50 \%)$ reported acute headache. Patients in 31 cases $(63.3 \%)$ had nonserviceable hearing. In 4 cases $(8.2 \%)$, the patients presented with symptomatic hydrocephalus, which was treated with external ventricular drain placement. Of these, 2 (4.1\%) 
TABLE 1. Demographics and general information of patients with cystic and solid VSs

\begin{tabular}{|c|c|c|c|}
\hline Variable & CVS (n=33) & SVS $(n=49)$ & p Value \\
\hline Mean age (range), yrs & $52.2(17-77)$ & $49.9(21-75)$ & 0.43 \\
\hline $\operatorname{Sex}^{*}$ & & & 0.49 \\
\hline Male & $20(62.5)$ & $26(53.1)$ & \\
\hline Female & $12(37.5)$ & $23(46.9)$ & \\
\hline Tumor side & & & 0.25 \\
\hline $\mathrm{Lt}$ & $16(48.5)$ & $31(63.3)$ & \\
\hline Rt & $17(51.5)$ & $18(36.7)$ & \\
\hline Mean tumor size (range), cm & $3.6(1.5-5)$ & $3(2-4.5)$ & $0.005 \dagger$ \\
\hline Tumor extension class & & & 0.6 \\
\hline $\mathrm{T} 3(\mathrm{a}+\mathrm{b})$ & $7(21.2)$ & $14(28.6)$ & \\
\hline $\mathrm{T} 4(\mathrm{a}+\mathrm{b})$ & $26(78.8)$ & $35(71.4)$ & \\
\hline $\begin{array}{l}\text { Mean duration of symptoms } \\
\text { (range), mos }\end{array}$ & $15.7(0.7-84)$ & $23.9(0.5-180)$ & $0.003 \dagger$ \\
\hline $\begin{array}{l}\text { Worsening/acute onset of } \\
\text { symptoms }\end{array}$ & $12(36.4)$ & $4(8.2)$ & $0.003 \dagger$ \\
\hline \multicolumn{4}{|l|}{ Surgical approach } \\
\hline Translabyrinthine & $24(72.7)$ & $29(59.2)$ & \\
\hline Retrosigmoid & $6(18.2)$ & $20(40.8)$ & \\
\hline Staged resection & $3(9.1)$ & & \\
\hline \multicolumn{4}{|l|}{ Extent of resection } \\
\hline GTR & $30(90.9)$ & $37(75.5)$ & 0.08 \\
\hline NTR & $2(6.1)$ & $5(10.2)$ & \\
\hline STR & $1(3)$ & $7(14.3)$ & \\
\hline \multicolumn{4}{|l|}{ Complications } \\
\hline Incisional CSF leak & $4(12.1)$ & $6(12.2)$ & $>0.99$ \\
\hline Wound infection & $2(6.1)$ & $2(4.1)$ & \\
\hline Sixth nerve palsy & $2(6.1)$ & & \\
\hline Rhinorrhea & $1(3)$ & $2(4.1)$ & \\
\hline Otorrhea & $1(3)$ & & \\
\hline $\begin{array}{l}\text { Transient swallowing } \\
\text { difficulty }\end{array}$ & $1(3)$ & & \\
\hline Facial dyskinesia & $1(3)$ & & \\
\hline Surgical site hematoma & $1(3)$ & & \\
\hline Aspiration pneumonia & & $1(2)$ & \\
\hline
\end{tabular}

CVS and SVS values are reported as the number of cases (\%) unless indicated otherwise.

* Presented as the number of patients (\%).

$\dagger p<0.05$.

required VP shunt placement postoperatively. The mean follow-up period was 35.6 months (range 2-101 months).

\section{Tumor Characteristics}

Sixteen of the CVSs (48.5\%) and 31 of the SVSs $(63.3 \%)$ were located on the left side, while $17(51.5 \%)$ of the CVSs and $18(36.7 \%)$ of the SVSs were on the right side. No significant differences regarding tumor side were found between the groups $(\mathrm{p}=0.25)$. The mean tumor size in the CVS group was $3.6 \mathrm{~cm}$ (range $1.5-5 \mathrm{~cm}$ ) and that of the SVS was $3 \mathrm{~cm}$ (range $2-4.5 \mathrm{~cm}$ ). This finding was statistically significant $(\mathrm{p}=0.005)$. Two $(6.1 \%)$ of
TABLE 2. Clinical presentation of patients with cystic and solid VSs

\begin{tabular}{lcc}
\hline \multirow{2}{*}{ Symptoms } & \multicolumn{2}{c}{ No. of Cases (\%) } \\
\cline { 2 - 3 } & CVS & SVS \\
\hline Hearing loss & $24(72.7)$ & $47(95.9)$ \\
\hline Tinnitus & $14(42.4)$ & $23(46.9)$ \\
\hline Balance difficulties & $12(36.4)$ & $16(32.6)$ \\
\hline Headache & $6(18.2)$ & $6(12.2)$ \\
\hline Vertigo/dizziness & $4(12.1)$ & $10(20.4)$ \\
\hline Facial sensory disturbance & $6(18.2)$ & $7(14.3)$ \\
\hline Ear pain/fullness & $4(12.1)$ & $3(6.1)$ \\
\hline Facial pain & $3(9.1)$ & $1(2)$ \\
\hline Swallowing difficulties & $3(9.1)$ & $2(4.1)$ \\
\hline Dysgeusia & $1(3)$ & $2(4.1)$ \\
\hline Hydrocephalus & $4(12.1)$ & $4(8.2)$ \\
\hline Incidentally diagnosed & $2(6.1)$ & $1(2)$ \\
\hline
\end{tabular}

the CVSs were class in T3a, while 5 (15.1\%), 10 (30.3\%), and $16(48.5 \%)$ of them were in classes T3b, T4a, and T4b, respectively. Three of the SVSs $(6.1 \%)$ were in class T3a, while $11(22.5 \%), 20(40.8 \%)$, and $15(30.6 \%)$ of them were in classes T3b, T4a, and T4b, respectively (Table 1). There was no significant difference in tumor class between the CVS and SVS groups $(p=0.6)$. All cysts were located medially with or without concomitant lateral cysts in the CVS group. Seven of the cystic tumors (21.2\%) contained large central thick-walled cysts, and 9 of them (27.3\%) harbored single large thin-walled cysts, while 2 (6.1\%), 7 (21.2\%), and $8(24.2 \%)$ of the tumors had multiple large thin-walled cysts, multiple small thick-walled cysts, or a mixed pattern of small and large cysts, respectively (Table 3 ).

\section{Surgery}

All but 3 operations (9.1\%) were performed in a single session in the CVS group. One of these 3 patients (3\%) underwent a translabyrinthine approach, followed by a retrosigmoid approach for recurrent CVS 8 years after the initial GTR via retrosigmoid approach. The remaining 2 patients underwent surgery in 2 sessions via retrosigmoid approach, which was followed by translabyrinthine approach 4 and 10 days apart from each other. In the CVS group, patients in 6 cases $(18.2 \%)$ underwent a retrosigmoid approach, and 24 (72.7\%) underwent a translabyrinthine approach. All operations were performed in a single stage in the SVS group via either a retrosigmoid approach $(\mathrm{n}=20,40.8 \%)$ or a translabyrinthine approach $(\mathrm{n}=29$, 59.2\%; Fig. 1).

GTR was achieved in 30 CVSs $(90.9 \%)$ and 37 SVSs (75.5\%), while STR was possible in $1(3 \%)$ and $7(14.3 \%)$ CVS and SVS resections, respectively. NTR was achieved in $2(6.1 \%)$ CVS and $5(10.2 \%)$ SVS surgeries. The rate of GTR was not statistically significant between the 2 groups $(p=0.08)$. The main reason for NTR or STR was hypervascularity or adherence of the tumor to the brainstem and/or FN in both groups. The tumor recurred in 1 CVS patient (3\%) 8 years after initial GTR and required 
TABLE 3. Distribution of cystic tumors depending on the cyst pattern

\begin{tabular}{lllll}
\hline & \multirow{2}{*}{ No. of } & \multicolumn{3}{c}{ Poor Facial Nerve Function $^{*}$} \\
\cline { 3 - 5 } & Tumors & Discharge & 3 Mos & $1 \mathrm{Yr}$ \\
\hline Multiple large thin-walled cysts & $2(6.1)$ & $1(50)$ & $1(50)$ & $0(0)$ \\
\hline Multiple small thick-walled cysts & $7(21.2)$ & $0(0)$ & $0(0)$ & $0(0)$ \\
\hline Single large thin-walled cysts & $9(27.3)$ & $2(22.2)$ & $0(0)$ & $0(0)$ \\
\hline Large central thick-walled cysts & $7(21.2)$ & $2(28.6)$ & $1(14.3)$ & $0(0)$ \\
\hline Mixed pattern of small \& large cysts & $8(24.2)$ & $2(25)$ & $1(12.5)$ & $0(0)$ \\
\hline
\end{tabular}

${ }^{*}$ Values are reported as the number of cases (\%).

reoperation. None of the CVS patients with NTR or STR required further treatment due to symptomatic regrowth during the mean follow-up period of 41.6 months (range $18-82$ months). Patients in 2 cases (4.1\%) with residual SVS required stereotactic radiosurgery, while the remaining 10 (20.4\%) did not have symptomatic regrowth of their tumor that required intervention during the mean followup period of 97.2 months (range 73-138 months; Fig. 2).

The distribution of patients on the basis of postoperative FN function is presented in Table 4. Although good FN function was significantly higher in the SVS group at discharge $(p=0.02)$, there was no significant difference between the groups 1 year after surgery ( $p=0.74$; Fig. 3 ).
When favorable FN function is defined as HouseBrackmann grades I-III, $63.6 \%$ of CVSs and $81.6 \%$ of SVSs were associated with favorable FN function at discharge. At the 3-month follow-up, FN function improved to favorable in $78.8 \%$ and $91.8 \%$ of cases of CVS and SVS, respectively. FN function continued to improve, and all patients in the CVS group showed favorable FN function at the 1-year follow-up. In the SVS group, favorable FN function was achieved in $97.8 \%$ of patients at the 1-year followup. There was no significant difference between the groups in terms of favorable FN function at discharge $(\mathrm{p}=0.07)$ or the 3-month $(p=0.1)$ and 1-year $(p>0.99)$ follow-ups.

At discharge, poor FN outcomes were observed after
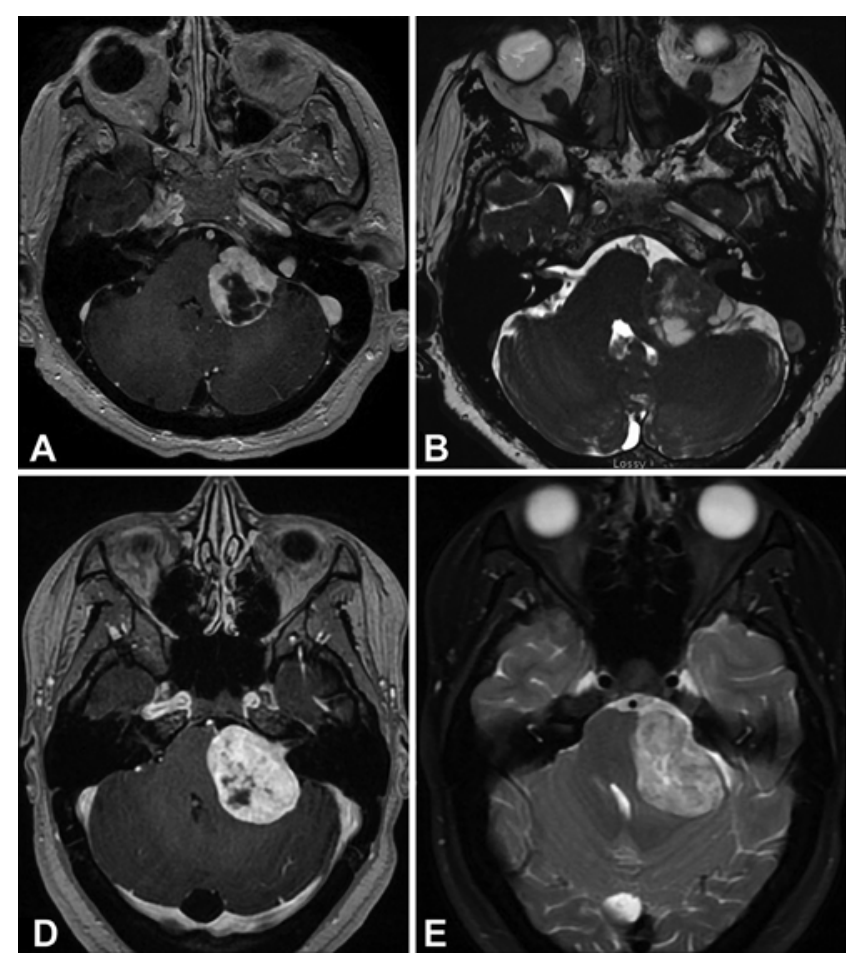
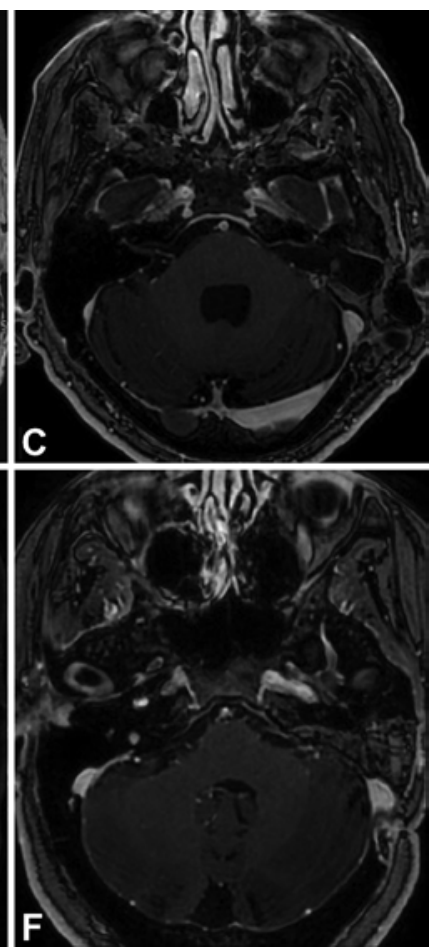

FIG. 1. Axial T1-weighted postcontrast and T2-weighted MR images obtained in CVS and SVS patients who underwent GTR via a translabyrinthine approach. A and B: Preoperative T1-weighted postcontrast (A) and T2-weighted (B) images obtained in a 48-year-old woman who presented with hearing loss, progressive imbalance, and gait difficulties. C: T1-weighted postcontrast image showing GTR of a CVS via a translabyrinthine approach. This patient had House-Brackmann grade II FN function at discharge, which improved to grade I at the 3-month follow-up. D and E: Preoperative T1-weighted postcontrast (D) and T2-weighted (E) images obtained in a 22-year-old woman who presented with hearing loss and dizziness. F: T1-weighted postcontrast image showing GTR of SVS via a translabyrinthine approach. This patient had House-Brackmann grade I FN function right after surgery, which remained grade I at the 1-year follow-up. 


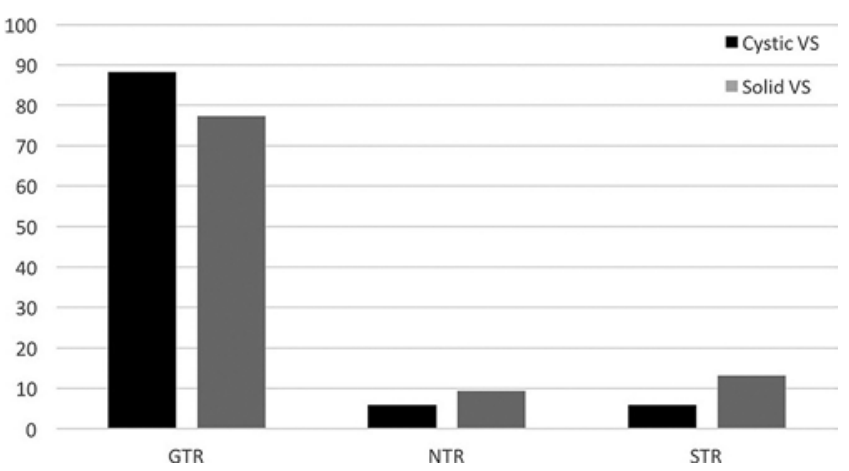

FIG. 2. Bar graph showing resection rates in the cystic (black) and solid (gray) VS groups.

resection of 2 of the tumors with single large thin-walled cysts (grade VI in 2; 22.2\%) and 1 of the tumors with multiple large thin-walled cysts (grade VI in $1 ; 50 \%$ ) at discharge. Similarly, poor FN outcomes were observed in 2 cases of large central thick-walled cysts (grade V in 1, grade VI in $1 ; 28.6 \%$ ) and 2 of those with a mixed pattern of small and large cysts (grade V in 1, grade VI in 1; $25 \%$ ) at discharge. Poor FN function was not observed in patients with multiple small thick-walled cysts. One year after surgery, no patient in the CVS group had poor FN function (Table 3).

\section{Complications}

None of the patients died after VS surgery. The most common complication was a CSF leak from the incision site, which was the case in $4(12.1 \%)$ of the CVS and 6 (12.2\%) of the SVS surgeries. The rate of CSF leak was not significantly different between the groups $(\mathrm{p}=1)$. One (3\%) of the leaks in the CVS group was managed conservatively, while 3 others $(9.1 \%)$ required lumbar drain insertion. One (3\%) of these required further treatment with VP shunt placement. In the SVS group, 1 of the leaks (2\%) was treated successfully with conservative treatment, while the remaining $5(10.2 \%)$ required lumbar drain insertion. Patients in 2 CVS cases (6.1\%) experienced a wound infection, one of whom responded to antibiotic treatment and the other required surgical debridement. Wound infection occurred in 2 SVS cases (4.1\%), and both were treated with antibiotics. Sixth nerve palsy occurred in 2 CVS cases (6.1\%), and both improved completely. Transient swallowing difficulty, otorrhea, rhinorrhea, facial dyskinesia, and postoperative hematoma developed, with an incidence of 3\% ( $=1)$ for each after CVS surgery. Otorrhea was not observed in SVS patients, while rhinorrhea developed in 2 cases $(4.1 \%)$. One of these cases was treated with lumbar drain placement while the other required surgical repair. One patient (2\%) in the SVS group experienced aspiration pneumonia, which was successfully treated via appropriate antibiotics (Table 1).

\section{Discussion}

Cystic VSs are notorious for rapid growth, unpredictable biological and clinical behavior, less-favorable surgical outcomes, increased perioperative complications, and postoperative morbidity and mortality. $2,6,7,11,18,20,24,32,35$ The reported incidence of CVS ranges between $4 \%$ and $48 \%$, most likely due to the different selection criteria used.,5, 11,15,19,28,35,36 While several studies have defined CVS based on the volume or size of the cyst relative to total tumor burden, ${ }^{10,27}$ corroboration of MRI findings with intraoperative visualization of cystic components has been the most commonly accepted criteria in defining a CVS. ${ }^{17,22,24}$, 28,35,37 Additionally, a higher incidence of CVS is encountered when larger tumors are taken into account, given the increased risk of intratumoral hemorrhage, degeneration, and necrosis resulting in subsequent cyst formation. ${ }^{6,7,17}$, 22,24,25,27,37 Consistently, CVSs in our series accounted for $38.6 \%$ of all class T3 and T4 VSs, while they made up only the $16.1 \%$ of overall VSs. Similarly, the mean tumor size in this group was larger than that in the SVS group on admission (3.6 cm vs $3 \mathrm{~cm})$ with a statistically significant difference $(p=0.005)$.

Although VSs are known to be slow-growing tumors, ${ }^{34}$ CVSs are often associated with rapid expansion of the cyst and a shorter symptom duration. ${ }^{6,12,36}$ Consistently, the mean duration of symptoms was significantly lower in our cystic tumors (15.7 months vs 23.9 months, $\mathrm{p}=0.003$ ). The rate of worsening/acute onset of symptoms was sig-

TABLE 4. Facial nerve function in CVS versus SVS cases at discharge and 3 months and 1 year postoperatively

\begin{tabular}{|c|c|c|c|c|c|c|}
\hline \multirow{3}{*}{$\begin{array}{l}\text { House- } \\
\text { Brackmann } \\
\text { Grade }\end{array}$} & \multicolumn{6}{|c|}{ No. of Cases (\%) } \\
\hline & \multicolumn{2}{|c|}{ Discharge } & \multicolumn{2}{|c|}{3 Mos } & \multicolumn{2}{|c|}{$1 \mathrm{Yr}$} \\
\hline & CVS & SVS & CVS & SVS & CVS & SVS \\
\hline \multicolumn{7}{|l|}{ Good } \\
\hline 1 & $9(27.3)$ & $29(59.2)$ & $15(45.5)$ & $37(75.5)$ & $18(66.7)$ & $38(84.4)$ \\
\hline II & $6(18.2)$ & $6(12.2)$ & $5(15.1)$ & $4(8.2 \%)$ & $4(14.8)$ & $4(8.9)$ \\
\hline \multicolumn{7}{|l|}{ Fair } \\
\hline III & $6(18.2)$ & $5(10.2)$ & $6(18.2)$ & $4(8.2)$ & $5(18.5)$ & $2(4.4)$ \\
\hline IV & $5(15.1)$ & $5(10.2)$ & $4(12.1)$ & $2(4.1)$ & $0(0)$ & $0(0)$ \\
\hline Poor & & & & & $0(0)$ & $0(0)$ \\
\hline V & $2(6.1)$ & $2(4.1)$ & $2(6.1)$ & $2(4.1)$ & $0(0)$ & $0(0)$ \\
\hline $\mathrm{VI}$ & $5(15.1)$ & $2(4.1)$ & $1(3)$ & $0(0)$ & $0(0)$ & $0(0)$ \\
\hline
\end{tabular}



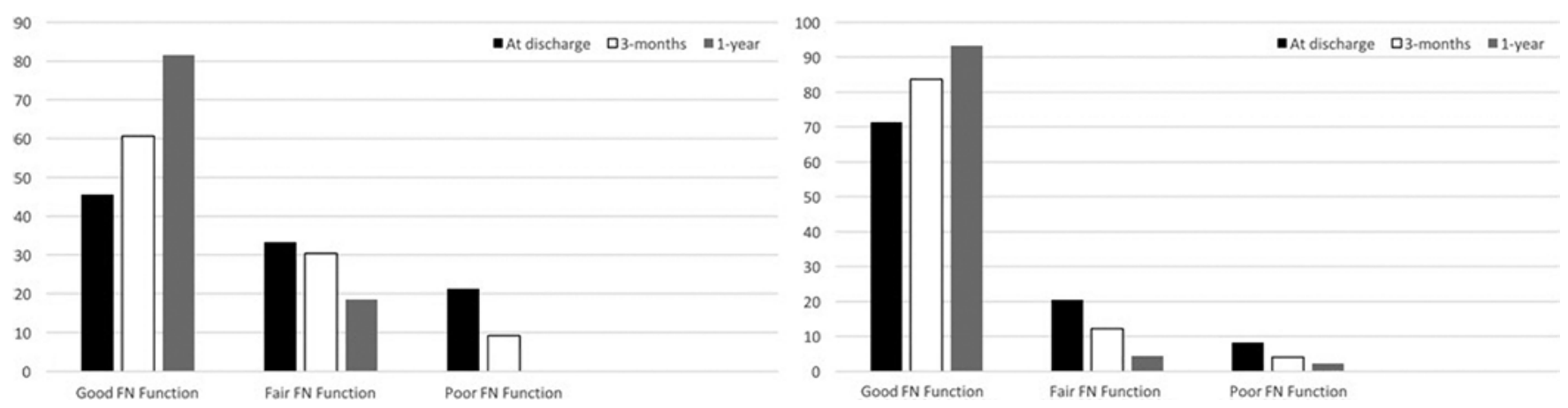

FIG. 3. Bar graph showing FN outcome (good, fair, and poor) in the cystic (left) and solid (right) VS groups at discharge from the hospital (black), 3 months (white), and 1 year (gray) postoperatively.

nificantly higher in the CVS group as well (36.4\% vs $8.2 \%$, $\mathrm{p}=0.003$ ). Moreover, $6.1 \%$ of the patients with CVS presented acutely with a decreased level of consciousness requiring emergency neurosurgical intervention.

Patients with class T3 and T4 CVSs may not be candidates for observation only, given the risk of sudden expansion of the cyst, possibly leading to acute and lifethreatening brainstem and fourth ventricle compression and subsequent hydrocephalus. Radiosurgery is a commonly accepted and effective indication in the management of small- and medium-sized VSs. Moreover, there is a growing tendency toward the application of radiosurgery in the management of CVSs. Promising results following Gamma Knife radiosurgery with a significant decrease in overall tumor volume in $80 \%$ of CVSs and overall tumor control rates up to $96.4 \%$ at 5 years have been reported recently. ${ }^{3,10}$ However, postprocedural transient enlargement of the cyst and intratumoral hemorrhage are serious consequences of radiosurgery and may cause neurological worsening or even death.,12,27,39 Thus, larger tumor sizes at presentation may preclude radiosurgery as an option in the management of a CVS causing symptomatic or radiological brainstem compression. Moreover, surgery after failed radiosurgery may result in decreased rates of GTR as well as increased morbidity due to adhesions and thickening and increased hypervascularity of the tumor capsule. ${ }^{26}$ We believe that, in cases of large cystic tumors with brainstem compression, microsurgical resection remains the treatment of choice whenever GTR or NTR is possible. ${ }^{2,11}$ Nonetheless, multicenter comparative studies with large numbers of patients and longer follow-up periods are warranted to compare the efficacy of radiosurgery versus microsurgery in the management of large CVSs. Longterm tumor control rates after stereotactic radiosurgery have been reported to be between $75 \%$ and $90.5 \%$ in SVSs larger than $3 \mathrm{~cm}$, with FN preservation rates between $70 \%$ and $100 \% .8,13,23,40,41,44,45$ In the present study, a tumor control rate of $95.9 \%$ with $93.3 \%$ of good FN outcome at the 1-year follow-up in the SVS group may suggest the validity of microsurgical resection, even in SVS treatment in the current radiosurgery era.

Preservation of FN function and complete resection of the tumor are the major goals of VS surgery. Several authors have reported that resection of a cystic tumor is associated with worse surgical outcomes in terms of GTR rates and FN function, 5,11,18,24,35,37,42,43 while few studies have reported similar FN outcomes between CVSs and SVSs. ${ }^{2,16,17,28}$ The main challenges in resection of CVSs are high vascularity of the solid portion and difficulties in preserving the arachnoid plane. Unpredictable displacement of the cranial nerves and peritumoral adhesions contribute to the complexity of surgery as well. ${ }^{2,24,28,29,35}$ Some studies have found that larger CVS size, rather than their cystic nature, can result in poorer FN outcomes. Better FN preservation rates due to earlier identification of the nerve after faster and earlier decompression of the cyst in thick-walled types have also been reported. ${ }^{21}$ However, finding a welldefined plane between the arachnoid and tumor capsule is challenging when dealing with thin-walled cysts due to the risk of unnoticed and accidental penetration of the brainstem by passing through the cyst. ${ }^{21,28}$ Similarly, medially located cysts have been reported to cause worse postoperative FN outcomes when compared with centrally located cysts. ${ }^{20,28,38}$ In our series, poor FN function was highest in the multiple large thin-walled cysts $(50 \%)$ at discharge. However, 1 year after surgery, none of the patients in the CVS group had poor FN function. We are in agreement that maintaining the dissection plane along the tumor periphery is more challenging in cases of peripherally located thin-walled cysts.

The reported rates of GTR after CVS surgery range between $44 \%$ and $94.6 \%, 22,28,35,37$ depending on the size and extension of the tumor, history of previous treatment, and the surgeon's experience. ${ }^{26,28,31}$ In the present study, the rate of GTR was not significantly different between CVSs and SVSs $(p=0.08)$. Although residual CVSs have been reported to be associated with rapid regrowth requiring reoperation, ${ }^{18,35}$ we have not observed regrowth in any of our patients with residual CVSs. Interestingly, recurrence occurred only in $1(3 \%)$ of the CVS patients 8 years after initial GTR, requiring reoperation.

In our series, the FN was anatomically preserved in all patients. Regardless of the criteria used, long-term FN outcome showed no difference between the groups. The only difference was observed at discharge $(45.5 \%$ good outcome for CVSs vs $71.4 \%$ in SVSs). Although short-term results may support the common perception that CVSs are associated with a lower rate of good FN outcome, our longterm results do not confirm such an association. Therefore, we strongly suggest that every single attempt to preserve 
FN function should be made at surgery, since even poorly or nonfunctioning FNs may improve to some degree in the long term if they are anatomically uninterrupted. ${ }^{4}$

Despite higher rates of good FN outcome with no major morbidity or mortality, the major limitation of this study is the retrospective analysis of the patient data, which might have introduced a selection bias. Additionally, there might be a referral bias toward more surgical cases. Nevertheless, even with these limitations, we believe that achieving high rates of favorable outcome in complex VS cases might be stimulating and encouraging for neurosurgeons and neurootologists in an era where more and more radiosurgery has been used in the treatment of VSs.

\section{Conclusions}

Cystic VS is a common subtype of VS with a more unpredictable behavior when compared with SVS. Preservation of FN function is one of the major goals of VS surgery, and GTR is another. Additionally, surgical treatment of a CVS does not necessarily result in poor surgical outcomes in terms of the extent of resection and FN outcome. Special care should be exercised to preserve anatomical continuity of the FN during surgery, since long-term FN outcomes are much more satisfactory than short-term results. High rates of GTR and good FN outcomes in the present study may also suggest that microsurgery stands as the treatment of choice in select cases of large CVSs and SVSs in the radiosurgery era.

\section{References}

1. American Academy of Otolaryngology-Head and Neck Surgery Foundation: Committee on Hearing and Equilibrium guidelines for the evaluation of hearing preservation in acoustic neuroma (vestibular schwannoma). American Academy of Otolaryngology-Head and Neck Surgery Foundation, INC. Otolaryngol Head Neck Surg 113:179-180, 1995

2. Benech F, Perez R, Fontanella MM, Morra B, Albera R, Ducati A: Cystic versus solid vestibular schwannomas: a series of 80 grade III-IV patients. Neurosurg Rev 28:209-213, 2005

3. Bowden G, Cavaleri J, Monaco E III, Niranjan A, Flickinger J, Lunsford LD: Cystic vestibular schwannomas respond best to radiosurgery. Neurosurgery 81:490-497, 2017

4. Carlson ML, Van Abel KM, Schmitt WR, Driscoll CL, Neff BA, Link MJ: The anatomically intact but electrically unresponsive facial nerve in vestibular schwannoma surgery. Neurosurgery 71:1125-1130, 2012

5. Charabi S: Acoustic neuroma/vestibular schwannoma in vivo and in vitro growth models. A clinical and experimental study. Acta Otolaryngol Suppl 530:1-27, 1997

6. Charabi S, Klinken L, Tos M, Thomsen J: Histopathology and growth pattern of cystic acoustic neuromas. Laryngoscope 104:1348-1352, 1994

7. Charabi S, Tos M, Børgesen SE, Thomsen J: Cystic acoustic neuromas. Results of translabyrinthine surgery. Arch Otolaryngol Head Neck Surg 120:1333-1338, 1994

8. Chung WY, Pan DH, Lee CC, Wu HM, Liu KD, Yen YS, et al: Large vestibular schwannomas treated by Gamma Knife surgery: long-term outcomes. J Neurosurg 113 Suppl:112121,2010

9. de Ipolyi AR, Yang I, Buckley A, Barbaro NM, Cheung SW, Parsa AT: Fluctuating response of a cystic vestibular schwannoma to radiosurgery: case report. Neurosurgery 62:E1164E1165, 2008
10. Frisch CD, Jacob JT, Carlson ML, Foote RL, Driscoll CLW, Neff BA, et al: Stereotactic radiosurgery for cystic vestibular schwannomas. Neurosurgery 80:112-118, 2017

11. Fundová P, Charabi S, Tos M, Thomsen J: Cystic vestibular schwannoma: surgical outcome. J Laryngol Otol 114:935939, 2000

12. Ganslandt O, Fahrig A, Strauss C: Hemorrhage into cystic vestibular schwannoma following stereotactic radiation therapy. Zentralbl Neurochir 69:204-206, 2008

13. Huang CW, Tu HT, Chuang CY, Chang CS, Chou HH, Lee MT, et al: Gamma Knife radiosurgery for large vestibular schwannomas greater than $3 \mathrm{~cm}$ in diameter. J Neurosurg 14:1-8, 2017

14. House JW, Brackmann DE: Facial nerve grading system. Otolaryngol Head Neck Surg 93:146-147, 1985

15. Jeng CM, Huang JS, Lee WY, Wang YC, Kung CH, Lau MK: Magnetic resonance imaging of acoustic schwannomas. J Formos Med Assoc 94:487-493, 1995

16. Jian BJ, Sughrue ME, Kaur R, Rutkowski MJ, Kane AJ, Kaur $\mathrm{G}$, et al: Implications of cystic features in vestibular schwannomas of patients undergoing microsurgical resection. Neurosurgery 68:874-880, 2011

17. Jones SEM, Baguley DM, Moffat DA: Are facial nerve outcomes worse following surgery for cystic vestibular schwannoma? Skull Base 17:281-284, 2007

18. Kameyama S, Tanaka R, Kawaguchi T, Fukuda M, Oyanagi K: Cystic acoustic neurinomas: studies of 14 cases. Acta Neurochir (Wien) 138:695-699, 1996

19. Kendall B, Symon L: Investigation of patients presenting with cerebellopontine angle syndromes. Neuroradiology 13:65-84, 1977

20. Mathies C, Samii M, Krebs S: Management of vestibular schwannomas (acoustic neuromas): radiological features in 202 cases - their value for diagnosis and their predictive importance. Neurosurgery 40:469-481, 1997

21. Mehrotra N, Behari S, Pal L, Banerji D, Sahu RN, Jain VK: Giant vestibular schwannomas: focusing on the differences between the solid and the cystic variants. Br J Neurosurg 22:550-556, 2008

22. Metwali H, Samii M, Samii A, Gerganov V: The peculiar cystic vestibular schwannoma: a single-center experience. World Neurosurg 82:1271-1275, 2014

23. Milligan BD, Pollock BE, Foote RL, Link MJ: Long-term tumor control and cranial nerve outcomes following Gamma Knife surgery for larger-volume vestibular schwannomas. J Neurosurg 116:598-604, 2012

24. Moon KS, Jung S, Seo SK, Jung TY, Kim IY, Ryu HH, et al: Cystic vestibular schwannomas: a possible role of matrix metalloproteinase- 2 in cyst development and unfavorable surgical outcome. J Neurosurg 106:866-871, 2007

25. Muzumdar DP, Goel A, Pakhmode CK: Multicystic acoustic neurinoma: report of two cases. J Clin Neurosci 9:453-455, 2002

26. Nonaka Y, Fukushima T, Watanabe K, Friedman AH, Cunningham CD III, Zomorodi AR: Surgical management of vestibular schwannomas after failed radiation treatment. Neurosurg Rev 39:303-312, 2016

27. Pendl G, Gantz JC, Kitz K, Eustacchio S: Acoustic neurinomas with macrocysts treated with Gamma Knife radiosurgery. Stereotact Funct Neurosurg 66 (Suppl 1):103-111, 1996

28. Piccirillo E, Wiet MR, Flanagan S, Dispenza F, Giannuzzi A, Mancini F, et al: Cystic vestibular schwannoma: classification, management, and facial nerve outcomes. Otol Neurotol 30:826-834, 2009

29. Preston-Martin S, Thomas DC, Wright WE, Henderson BE: Noise trauma in the aetiology of acoustic neuromas in men in Los Angeles County, 1978-1985. Br J Cancer 59:783-786, 1989 
30. Raheja A, Bowers CA, MacDonald JD, Shelton C, Gurgel RK, Brimley C, et al: Middle fossa approach for vestibular schwannoma: good hearing and facial nerve outcomes with low morbidity. World Neurosurg 92:37-46, 2016

31. Samii M, Gerganov V, Samii A: Improved preservation of hearing and facial nerve function in vestibular schwannoma surgery via the retrosigmoid approach in a series of 200 patients. J Neurosurg 105:527-535, 2006

32. Samii M, Matthies C: Management of 1000 vestibular schwannomas (acoustic neuromas): surgical management and results with an emphasis on complications and how to avoid them. Neurosurgery 40:11-23, 1997

33. Samii M, Metwali H, Gerganov V: Microsurgical management of vestibular schwannoma after failed previous surgery. J Neurosurg 125:1198-1203, 2016

34. Selesnick SH, Johnson G: Radiologic surveillance of acoustic neuromas. Am J Otol 19:846-849, 1998

35. Sinha S, Sharma BS: Cystic acoustic neuromas: surgical outcome in a series of 58 patients. J Clin Neurosci 15:511-515, 2008

36. Tali ET, Yuh WT, Nguyen HD, Feng G, Koci TM, Jinkins JR, et al: Cystic acoustic schwannomas: MR characteristics. AJNR Am J Neuroradiol 14:1241-1247, 1993

37. Tang IP, Freeman SR, Rutherford SA, Kong AT, Ramsden RT, Lloyd SKW: Surgical outcomes in cystic vestibular schwannoma versus solid vestibular schwannoma. Otol Neurotol 35:1266-1270, 2014

38. Thakur JD, Khan IS, Shorter CD, Sonig A, Gardner GL, Guthikonda B, et al: Do cystic vestibular schwannomas have worse surgical outcomes? Systematic analysis of the literature. Neurosurg Focus 33(3):E12, 2012

39. Unger F, Walch C, Haselsberger K, Papaefthymiou G, Trummer M, Eustacchio S, et al: Radiosurgery of vestibular schwannomas: a minimally invasive alternative to microsurgery. Acta Neurochir (Wien) 141:1281-1286, 1999

40. van de Langenberg R, Hanssens PE, Verheul JB, van Overbeeke JJ, Nelemans PJ, Dohmen AJ, et al: Management of large vestibular schwannoma. Part II. Primary Gamma Knife surgery: radiological and clinical aspects. J Neurosurg 115:885-893, 2011

41. Yang HC, Kano H, Awan NR, Lunsford LD, Niranjan A, Flickinger JC, et al: Gamma Knife radiosurgery for larger- volume vestibular schwannomas. Clinical article. J Neurosurg 114:801-807, 2011

42. Yashar P, Zada G, Harris B, Giannotta SL: Extent of resection and early postoperative outcomes following removal of cystic vestibular schwannomas: surgical experience over a decade and review of the literature. Neurosurg Focus 33(3):E13, 2012

43. Wandong S, Meng L, Xingang L, Yuguang L, Shugan Z, Lei W, et al: Cystic acoustic neuroma. J Clin Neurosci 12:253255,2005

44. Williams BJ, Xu Z, Salvetti DJ, McNeill IT, Larner J, Sheehan JP: Gamma Knife surgery for large vestibular schwannomas: a single-center retrospective case-matched comparison assessing the effect of lesion size. J Neurosurg 119:463-471, 2013

45. Zeiler FA, Bigder M, Kaufmann A, McDonald PJ, Fewer D, Butler J, et al: Gamma knife radiosurgery for large vestibular schwannomas: a Canadian experience. Can J Neurol Sci 40:342-347, 2013

\section{Disclosures}

The authors report no conflict of interest concerning the materials or methods used in this study or the findings specified in this paper.

\section{Author Contributions}

Conception and design: Başkaya, Eser Ocak. Acquisition of data: Eser Ocak, Dogan, U Ocak, Dinc. Analysis and interpretation of data: Eser Ocak. Drafting the article: Eser Ocak, Dogan. Critically revising the article: Başkaya. Reviewed submitted version of manuscript: Başkaya. Approved the final version of the manuscript on behalf of all authors: Başkaya. Statistical analysis: U Ocak. Administrative/technical/material support: Eser Ocak, Dogan.

\section{Correspondence}

Mustafa K. Baskaya: University of Wisconsin Medical School, Madison,WI. baskaya@neurosurgery.wisc.edu. 